\title{
The sound of your name
}

Cite as: CMAJ 2021 June 21;193:E965-6. doi: 10.1503/cmaj.210454

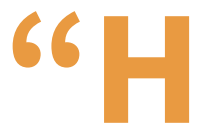

ave you been in the ICU before?" the surgical resident asks. I know she means as a medical student, not as a patient.

"No," I reply, although I could have told her about my own experience as a patient in ICU four years ago. But I didn't think she wanted to hear my personal story.

I remember the eerie whooshing sounds of the ventilator beside another patient's bed. The lights on all night, the nurses' voices. The steady shushing and bubbling of the nebulizer as moisture condensed on the inside of my oxygen mask.

I take a big breath.

"Nothing to be nervous about," the resident says.

We pull on yellow gowns over our surgical greens, then masks and gloves, abiding by infection-control rules posted on the door.

I remember my pale-blue hospital gown loosely tied at the back so it could be pulled down a little in the front to accommodate cardiac monitor leads and endless chest auscultations. Feeling embarrassed and exposed without the comforting warmth of my own pyjamas.

The resident slides the door open and beckons me to follow.

I remember the skritch of the curtains pulling back when doctors or nurses entered and when the respiratory tech came in to draw my blood gases again.

The patient lying in front of me is sedated, on a ventilator, a silver pole next to his bed with IV meds dripping into his vein. He looks so young.

I was 28 with severe pneumonia complicated by asthma, coughing and wheezing until my lips were blue. Struggling for breath like I was running a marathon, I tried to sleep propped up on pillows. Mostly I just lay awake, terrified by the sound of my own breathing.

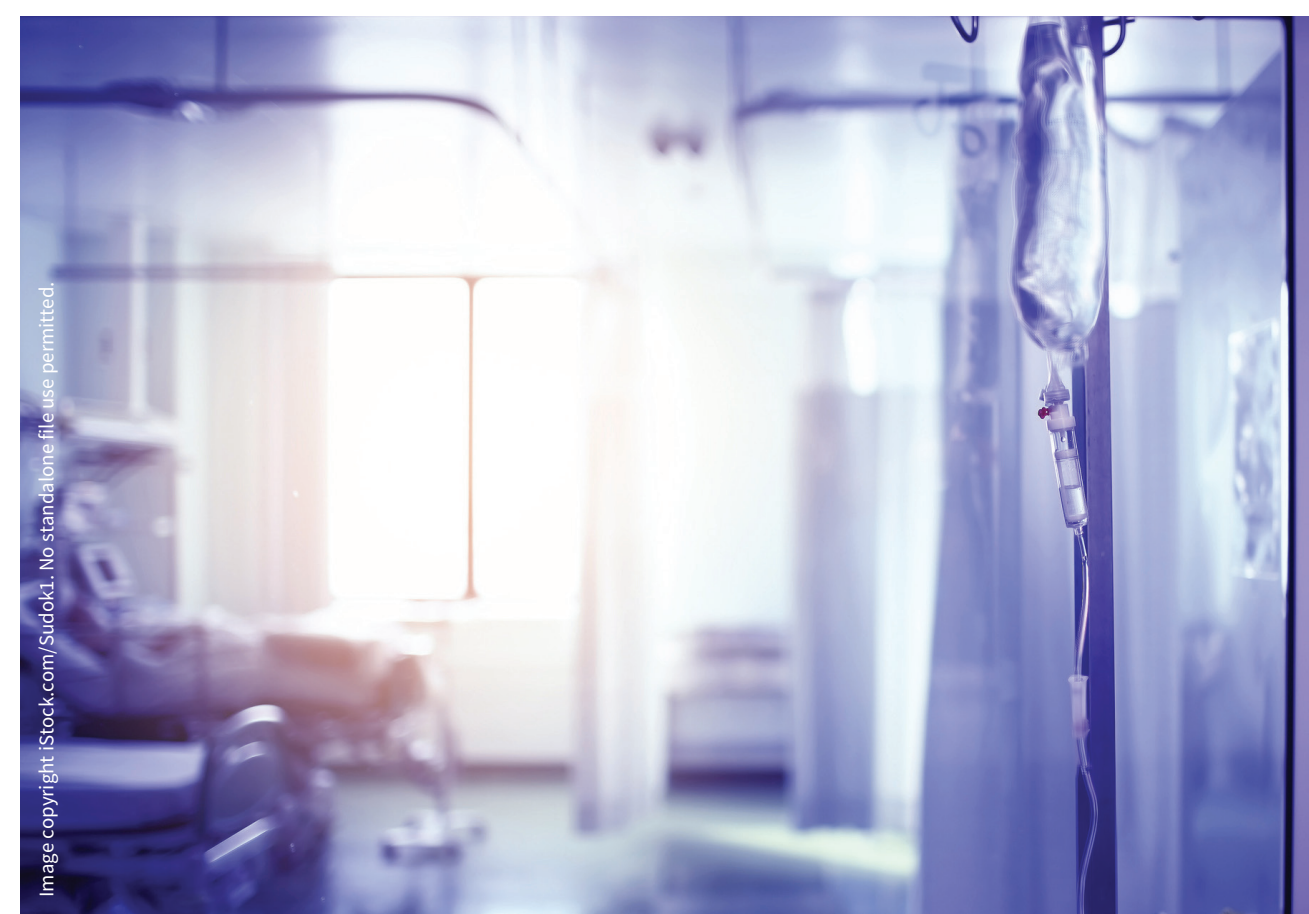

He's in his late twenties, with lightbrown hair curling over his forehead, long legs, his feet touching the end of the bed. Full cheeks make him seem even younger. He looks like a tender-hearted guy, the kind of guy my family would instantly like.

The room smells like antiseptic and old sneakers.

I remember that strange smell, and the patient crying in the bed next to mine. He cried behind the curtain while the nurse changed his bandages. I overheard the nurse say, "Sepsis," although I didn't know what it meant at the time.

"You'll get used to this smell," the resident whispers. "It helps if you tie your mask on tight."

No, I will never get used to this - not the smell, not any of this. Even if the mask is tied so tightly that I can barely breathe.

"He's eviscerated."

Our eyes meet as the resident tries to gauge my reaction, to see if I know what the word means. Then she pulls the sheet down.

"His belly's been reopened because of overwhelming sepsis after surgery for gallstone pancreatitis," she says.

My mind stops thinking for a moment; I force myself not to look away. His eyes open briefly as if in a dream - so briefly I almost think I imagined it. So briefly I couldn't tell if they were brown eyes or blue. Long, feathery eyelashes.

A nurse hovers over the patient as if she's protecting him from what we are about to do. She arranges packages of irrigation equipment, instruments, gauze, and lays sterile drapes around his belly.

I have no memories to compare to this. My shortness of breath and wheezing and coughing were terrible, but not like this.

As we cleanse and irrigate his belly, then pack with gauze, I mentally repeat that soon he will improve, sit up and be ready to leave the ICU. 
I said goodbye to the nurses as I was wheeled out of the ICU to a regular room for a few more days. I was impatient to go home.

Deep inside, I know his outcome will be different.

After the procedure, I walk to the window to look out to a soft, grey rain and I say a silent prayer for him. The nurse and the resident leave but I return to his bedside and linger for a moment to watch the steady rise and fall of his chest, his eyelashes fluttering as if he is dreaming. I wonder what he sees in his dreams, what he hears in this room.

I say his first name out loud, wanting the sound of his name to be heard clearly over the sound of the ventilator. $\mathrm{He}$ is someone's son; he is critically ill, and he may never leave this room. "We are trying our best to make you better," I say softly. "I know you just want to go home." My words seem futile in the quiet room.

I remember when I finally left the hospital, walked out into the sunlight, and felt cool, fresh air in my lungs. How grateful I was. How alive I felt.

I slide the glass door closed, remove my gown and gloves and drop them into the bin. The nurse looks up from her paperwork. Our eyes meet and she tries to smile.

At home that night, I put my son to bed, pull the blankets up over his belly, and brush wisps of curly hair from his forehead. I watch his eyelashes flutter as he falls asleep.

\section{Sharon McCutcheon MD}

Retired, Sussex, NB

This article has been peer reviewed.

This encounter occurred more than 25 years ago.

Content licence: This is an Open Access article distributed in accordance with the terms of the Creative Commons Attribution (CC BY-NC-ND 4.0) licence, which permits use, distribution and reproduction in any medium, provided that the original publication is properly cited, the use is noncommercial (i.e., research or educational use), and no modifications or adaptations are made. See: https://creativecommons. org/licenses/by-nc-nd/4.0/ 